\title{
ORIENTAÇÕES METODOLÓGICAS PARA UM ENSINO DE FILOSOFIA BASEADO EM VIRTUDES INTELECTUAIS
}

\author{
Matheus de Lima Rui ${ }^{1}$
}

RESUMO: Pretendo apresentar aqui a fundamentação de uma proposta metodológica para o ensino de Filosofia, a partir de insights sobre a concepção de "virtudes", elaborados, principalmente, pela autora contemporânea Linda Zagzebski, e marginalmente por Gilbert Ryle. Meu objetivo é sustentar que a mediação entre aluno e conhecimento não ocorre de forma mágica, ou numa relação passiva do aluno frente ao conteúdo exposto, mas envolve um contexto epistemológico relacionado a um conjunto de práticas e habilidades que estimulem as virtudes intelectuais necessárias para qualquer aprendizado. Para isso, inicialmente explico o que devemos entender por metodologia de ensino, dentro da concepção teórica desenvolvida. Em seguida, esclareço algumas noções sobre o que chamamos de "conhecimento", e sua relação com o aprendizado. Por fim, desenvolvo a ideia chave do trabalho a partir das considerações sobre virtudes intelectuais.

PALAVRAS-CHAVE: Aprendizado; Conhecimento; Ensino; Virtudes; Zagzebski. 


\begin{abstract}
My aim here, is to show the grounds for a methodological proposal for the teaching of philosophy, from insights about the conceptions of "virtues", produced mainly by the contemporary author Linda Zagzebski, and marginally by Gilbert Ryle. My goal is claim that, the mediation between student and knowledge does not occur magically, or from a passive relationship of the student in front of the exposed content, but involves an epistemological context related to a set of practices and skills that stimulate the intellectual virtues necessary for any learning. For this, first we explain what we understand by teaching methodology within the developed theoretical concept. Then clarify some notions of what we call "knowledge" and its relation to learning. Finally, develop the key idea of working from considerations of intellectual virtues.
\end{abstract}

KEYWORDS: Learning; Knowledge; Teaching; Virtues; Zagzebski. 


\section{CONSIDERAÇÕES INICIAIS}

A ideia de que o fundamento do ensino de filosofia deve ser baseado em virtudes intelectuais se deu pela seguinte razão: assumindo que uma das noções fundamentais sobre a ideia de "virtudes" é que elas são transmitidas por agentes virtuosos e são aprendidas por repetição e hábito dos mesmos, devemos pensar na função do professor como sendo o modelo de agente virtuoso para desenvolver tais virtudes em seus alunos. O grande problema é que, muitas das vezes, os professores exigem o desenvolvimento e aquisição de virtudes que nem os mesmos possuem. Como pretendo mostrar, a mediação entre aluno e conhecimento não ocorre de forma mágica, ou numa relação passiva do aluno frente ao conteúdo exposto, mas envolve um contexto epistemológico relacionado a um conjunto de práticas e habilidades que estimulem as virtudes intelectuais necessárias para qualquer aprendizado.

Pretendo apresentar aqui a fundamentação de uma proposta metodológica para o Ensino de Filosofia, a partir de insights sobre a concepção de "virtudes", elaborados, principalmente, pela autora contemporânea Linda Zagzebski. Em um primeiro momento, busco esclarecer alguns conceitos chave do estudo que está sendo aqui apresentado, juntamente com a tentativa de responder uma questão sobre a proposta teórico-metodológica, tendo em vista nossos propósitos: do que falamos quando falamos em metodologia? Em um segundo momento, pretendo apresentar alguns pontos filosóficos fundamentais sobre a ideia de conhecimento: Quais são os tipos de conhecimento? Como adquirimos conhecimento de algo? O que é o conhecimento? Por último, 
tento relacionar como as considerações sobre virtudes podem desempenhar um papel essencial em nossa prática docente, em conformidade com as posições apresentadas sobre conhecimento, aprendizado e metodologia. Portanto, pretendo começar desenvolvendo algumas considerações básicas sobre metodologia e ensino de filosofia, fundamentando minha orientação metodológica para um ensino de filosofia baseado em virtudes intelectuais. Para início de conversa, comecemos com algumas considerações introdutórias sobre o conceito principal de nosso problema, o conceito de "virtude".

Quando falamos sobre "virtude", automaticamente nos remetemos à filosofia grega, e particularmente à filosofia moral de Aristóteles. Porém, minha abordagem se dá por meio de uma retomada desta noção a partir da filosofia contemporânea, mais especificamente com a autora Linda Zagzebski na obra Virtues of the Mind (1996). Mas por que não utilizar Aristóteles? Tal escolha se deu principalmente por duas razões. Primeiro porque Aristóteles viveu a dois mil anos atrás, e o contexto social grego é indiscutivelmente diferente do que vivemos nos dias atuais. A mudança na sociedade e o desenvolvimento científico não pode ser um fator irrelevante quando pensamos na reutilização de um autor para o desenvolvimento de um problema contemporâneo. Em segundo lugar, vários movimentos contemporâneos se preocuparam em retomar algumas ideias de Aristóteles e ideias da filosofia grega em geral, e parte fundamental dessa retomada acontece na filosofia analítica contemporânea, reconhecida por sua clareza na escrita e seu rigor conceitual. Assim, deixamos de lado 
algumas dificuldades que acabariam ocorrendo na busca por interpretar exatamente alguns conceitos gregos, o que seria inevitável ao estudar um autor como Aristóteles. Logo, fazendo uma apropriação de autores como a Linda Zagzebski, evito todas as possíveis desvantagens mencionadas em se trabalhar diretamente com um autor clássico grego e, principalmente, evito ser alvo de objeções do tipo: "mas Aristóteles realmente disse isso?". Ao mesmo tempo, acredito não deixar a desejar em nenhum ponto no que diz respeito ao conteúdo do que será exposto.

Apesar da concepção de virtudes aqui apresentada estar centrada na filosofia de Zagzebski, minha posição teórica faz uso de alguns outros autores que podem contribuir para o assunto em questão. Algumas das ideias da filosofia contemporânea que muito utilizo aqui estão na obra de Gilbert Ryle, The concepto of Mind (1949), principalmente suas ideias sobre o "anti-intelectualismo" ${ }^{2}$ que irão desempenhar um papel fundamental no pano de fundo teórico da concepção didática que será apresentada. Portanto, por razões elucidativas, irei expor sucintamente algumas ideias chaves da filosofia de Ryle.

Em The concepto of Mind, um dos objetivos centrais de Ryle é esboçar uma análise do conceito de "mente", e suas ocorrências na história da filosofia. Com esse propósito, o autor também busca demonstrar que o dualismo cartesiano mente/corpo é uma posição equivocada. Embora os argumentos do autor sobre o dualismo mente/corpo não sejam um tópico fundamental em nossa discussão, veremos que as posições de Ryle sobre noções como "inteligência", "intelecto" e "racionalidade" têm sempre como pano de fundo 
uma reposta à concepção cartesiana de mente, de modo que Ryle vai se referir à posição Cartesiana apelidando-a de "O Fantasma na Máquina”. Mas no que tal discussão pode nos auxiliar aqui, quando o objetivo é fundamentar uma prática docente baseada em posições filosóficas? Veremos mais à frente que a noção de virtude intelectual está comprometida com alguns conceitos chave que podemos encontrar na filosofia de Ryle, e que tais conceitos mostram-se dentro do cotidiano escolar, quando falamos em aprendizado e inteligência. Primeiramente, é importante um esclarecimento inicial sobre o que Ryle chama de conceitos mentais, e como vou me apropriar desta concepção.

Podemos começar explicando alguns conceitos envolvidos no que reconhecemos como a atividade de "pensar". Aqui vão alguns dos adjetivos pertencentes a essa família de noções sobre o que cotidianamente chamamos de "mental" e que já estamos familiarizados: sensitivo, cuidadoso, metódico, prudente, lógico, crítico, etc. Ryle busca explicar como trabalhamos com algumas noções sobre o aprendizado e o conhecimento e o que acontece, por exemplo, em situações em que dizemos que alguém é esperto ou que falta inteligência a uma pessoa.

É importante notar primeiramente que o que chamamos de "estupidez" não é a mesma coisa, ou o mesmo tipo de coisa, que a "ignorância”, afirma Ryle. Não existe nenhuma incompatibilidade entre ser bem informado e ser bobo, e nenhum impedimento de que uma pessoa que tenha bom faro para argumentos tenha também uma cabeça ruim para os fatos. Parte da importância da distinção entre ser inteligente e possuir conhecimento repousa sobre o fato de 
que especialistas e leigos tendem a ameaçar as operações intelectuais como o coração do produto mental; isto é, eles definem todo tipo de conceito mental em termos de conceitos de cognição. Eles supõem que o exercício primário da mente consiste em encontrar respostas para questões e que as outras ocupações são meras aplicações das verdades já consideradas. Como o autor afirma: a ideia grega de que a imortalidade era reservada para a parte teórica da alma foi desacreditada, mas não dissipada, pelo Cristianismo (RYLE, 1949).

Segundo Ryle, são duas as combinações que fundamentam o dogma chamado "fantasma na máquina" (isto é, a concepção cartesiana dualista sobre a mente): a primeira consiste na ideia de que teorizar é uma atividade primaria da mente; a segunda afirma que teorizar é, intrinsecamente, uma operação privada, silenciosa ou interna. As pessoas tendem a identificar a mente como o lugar onde acontecem os pensamentos secretos. Supõe-se, além do mais, que existe algo misterioso a respeito de como é que nossos pensamentos se fazem públicos, sem dar-se conta de que empregamos artifícios especiais para mantêlos reservados para nós. Isto é, o pensamento é muito mais externo do que geralmente imaginamos.

Assim como Ryle, pretendo explicar que muitas das atividades que colocam em manifestação qualidades mentais não são, em si mesmas, operações intelectuais ou efeitos de operações intelectuais. A prática inteligente não é dependente da teoria, pelo contrário, teorizar é uma prática entre outras que pode ser feita com inteligência ou estupidez. Essa tese da filosofia de Ryle será fulcral, 
e terá diversas implicações, em nossa discussão final sobre as "virtudes intelectuais" como o fundamento de uma prática docente a partir do pensamento de Linda Zagzebski. Entretanto, como já foi dito, gostaria de esboçar algumas considerações sobre a proposta que aqui estamos apresentando, uma proposta metodológica.

\section{POR QUE NÃO UMA METODOLOGIA PRONTA? UMA ANÁLISE DO ARGUMENTO DO REGRESSO DE GILBERT RYLE}

Mais uma vez farei uso da filosofia de Ryle, não sobre um assunto que o mesmo tenha se preocupado diretamente, mas sobre o modo como podemos compreender seu "antiintelectualismo" dentro de um problema sobre métodos em filosofia. Como parece fundamental, devemos iniciar essa investigação com uma pequena pergunta: O que é um método? Tomemos como exemplo a definição oferecida por Jaqueline Russ (2010, p. 16): um método é um conjunto de procedimentos lógicos e racionais, que permitem chegar a um fim.

Retomando o tema central de nossa investigação, podemos dizer que, quando o assunto diz respeito à formação didática do professor, uma frase sempre aparece com devido destaque: "Não existe uma receita pronta!". Podemos interpretar isso de algumas formas distintas, mas assumirei que tal afirmação expressa a rejeição de um conjunto de regras que ditam o que o professor deve, ou não, fazer em sala de aula, um tipo de passo-a-passo. 
Como vimos, Jaqueline Russ afirma que um método é um conjunto de procedimento lógicos racionais. Mas qual é a viabilidade de aplicar esse conjunto de procedimentos, e o que seriam essas regras? Vamos analisar com uma pouco mais de preciosidade esse conceito de método e regras.

Penso que aqui a autora se refere à assimilação de regras (ou informações) que permitem a uma pessoa executar bem ou mal certa atividade, uma metodologia completa, contendo um conjunto de "regras proposicionais", parecendo implicar em uma receita. E como já foi dito: receita não existe!

Um conjunto de regras que seja capaz de orientar "normativamente" certa prática seria semelhante à assimilação de regras de xadrez, onde basta que você compreenda bem as regras para ser capaz de realizar a atividade de jogar xadrez com devido sucesso. Entretanto, segundo Ryle, um conjunto de regras assim assimiladas conduziria a um problema de regresso conceitual infinito. Vou explicar sua razão. Para o filósofo britânico, "quando se atribui a alguém predicados tais como 'astuto' ou 'bobo', 'prudente' ou 'imprudente', tal descrição não lhe atribui conhecimento ou ignorância de alguma verdade, mas sim uma habilidade para se fazer certo tipo de coisa" (RYLE, 1949 , p. 27). Pensemos que desse modo não existe um método "astuto" ou "bobo" por si mesmo.

Segundo o autor, existem muitos tipos de ações inteligentes cujas regras ou critérios não se encontram formuladas. "Uma pessoa é incapaz de responder quando se exige as máximas ou cânones de base para se fazer uma boa piada. De tal modo, a prática do humorista é independente de sua teoria" (RYLE, 1949, p. 27). Aqui parece existir uma 
lacuna entre o conteúdo do método a ser formulado e a habilidade de execução de tal atividade.

Quem acredita que todo tipo de ação ou atividade pode ser reduzida a um tipo de descrição informativa é chamado por Ryle como parte da "tradição intelectualista". A objeção decisiva ao legado intelectualista é a seguinte: "a consideração de proposições é em si mesma uma operação que pode ser executada de um modo mais ou menos inteligente ou torpe. Então, se para qualquer operação que possa ser executada inteligentemente se requer a execução prévia e inteligente de outra operação, é logicamente impossível romper o círculo" (RYLE, 1949, p. 30).

Assim Ryle explica:

Consideraremos alguns aspectos que dão origem a esse regresso. De acordo com o legado intelectualista, toda vez que alguém atua inteligentemente, seu ato é dirigido e precedido por outro ato interno que consiste em considerar uma proposição normativa apropriada. Porque um herói não considera em suas ações, regras como a de cozinhar ou regras pertencentes à lógica formal? $\mathrm{O}$ que faz que alguém tome a proposição apropriada ao invés de outra? A reflexão inteligente sobre o atuar consiste, entre outras coisas, em considerar o relevante e deixar de lado o inapropriado. Devemos então dizer para o herói que ele deve refletir melhor sobre seu ato para que sua ação seja inteligente? Este regresso infinito mostra que a aplicação de um critério apropriado não implica no reconhecimento de um processo que considere tal critério (RYLE, 1949, p. 31). 
Como veremos no tópico seguinte, Ryle trabalha com a uma distinção fundamental entre o conhecimento por habilidade (know-how) e o conhecimento por descrição (know-that). Argumentando contra o legado intelectualista, o autor pretende sustentar que existe um tipo de conhecimento, o know-how, que não pode ser redutível a uma descrição detalhada da execução. Logo, se entendemos que a prática docente dentro de uma sala de aula envolve uma habilidade de execução, é impossível que se construa um método com a capacidade de tornar uma aula boa ou má, por si mesma, independente da habilidade de execução daquele que ministra a aula.

Para o autor, a suposição absurda do legado intelectualista é, em termos gerais, que qualquer tipo de ação herda o título de inteligente de uma operação interna, anterior, que consiste em planejar o que fazer. Se somos tolos, nossos planos serão tolos, se somos inteligentes nossos planos serão inteligentes. Em consequência, de acordo com o argumento anteriormente apresentado, nosso processo de planejamento intelectual herda seu título de outro processo anterior, que consiste em planejar o plano, e esse processo pode ser, por sua vez, tolo ou astuto. Desse modo, o regresso é infinito e a reduz ao absurdo a teoria que sustenta que para uma operação ser inteligente ela deve estar precedida por uma operação prévia do tipo intelectual: "O que distingue os atos sensatos dos tolos não é seu parentesco e sim seu procedimento. Este tem aplicações não só para as ações intelectuais, mas também para as práticas" (RYLE, 1949, p. 31). 
Podemos reduzir as considerações sobre método aqui apresentadas da seguinte forma: se toda tarefa, tanto prática quanto intelectual, fosse resultado da assimilação e realização de um bom método, toda atividade seria boa se o método fosse bom, e seria ruim se o método fosse ruim. Entretanto, parece que este não é o caso. Baseando-se nas afirmações de Ryle, pretendo sustentar que uma didática fundamentada em virtudes intelectuais não pode ser resultado de uma metodologia dada, préestabelecida. Assim, a prática docente não pode ser o resultado de uma descoberta de regras fundamentais que podem ser transmitidas para outra pessoa em forma de uma metodologia, ou de uma "pedagogia da didática". Da mesma forma, a "didática virtuosa" envolve um conjunto de realização, tanto teóricas como práticas, assumindo que a habilidade de se ministrar uma boa aula não é algo que possa ser transmitido em informações. Entretanto, existe um modo em que ela pode ser compartilhada por outras pessoas de forma relativamente eficiente, que seria da seguinte maneira: "Olha só como eu faço, assim eu dou uma boa aula". Desse modo, como andar de bicicleta, dar uma aula não é uma habilidade que pode ser transmitida meramente através de proposições, ou a formulações de um conjunto de regras. Como veremos a seguir, a prática docente baseada em virtudes intelectuais, exige o trabalho esclarecido dos três tipos de conhecimento que reconhecemos na tradição filosófica, o conhecimento por habilidade, por descrição e por familiaridade. 


\section{TIPOS DE CONHECIMENTO E O PAPEL DO PROFESSOR}

Para investigar nossas questões sobre ensino e aprendizado, é inevitável que tenhamos de dar uma resposta sobre o que é o conhecimento e como ocorre seu aprendizado. Neste ponto, pretendo oferecer uma análise sobre quais são os tipos de conhecimento que existem e como ocorre o processo de aquisição dos mesmos.

Tradicionalmente, reconhecemos na filosofia três tipos fundamentais de conhecimento, o conhecimento por familiaridade, por habilidade e o conhecimento proposicional. O conhecimento por familiaridade (ou conhecimento direto) é resultado do contato do sujeito, através da experiência, com a porção de realidade conhecida. O conhecimento por habilidade (ou know-how) é aquele conhecimento que avalia se uma execução foi executada de forma mais ou menos excelente. E o conhecimento proposicional (ou know-that) é o que o sujeito conhece por meio de uma proposição, ou uma descrição informativa, verdadeira sobre o mundo.

O conhecimento por familiaridade é reconhecido, principalmente, a partir da filosofia de Bertrand Russel ${ }^{3}$. Um exemplo desse tipo de conhecimento seria quando um professor diz que crianças de 4 a 5 anos sabem o caminho que vai de casa até a escola e vice-versa Este saber é um saber por familiaridade, embora muitas vezes os professores não se preocupem exatamente com o que isso significa. Elas tinham familiaridade com aquele caminho, podemos dizer. O conhecimento por habilidade é dado, por exemplo, ao dizermos que alguém sabe andar de bicicleta, 
sabe jogar futebol e sabe falar inglês. Não se está dizendo que se tem conhecimento proposicional, mas que se têm o conhecimento de habilidades específicas para andar de bicicleta, jogar futebol e falar inglês.

O conhecimento proposicional, o que alguns chamam de conhecimento teórico, se dá quando um sujeito, por exemplo, diz saber que Porto Alegre é a capital do Rio Grande do Sul. Claro, não é necessário que seu conhecimento se dê por meio de experiência direta, mas de conhecimento geográfico. Ele pensa que as evidências para acreditar que o Porto Alegre é a capital do Rio Grande do Sul são mais fortes do que o contrário. Assim, o sujeito afirma conhecer esta proposição e, assim, atribuiríamos conhecimento a ele dizendo "S sabe que Porto Alegre é a capital do Rio Grande do Sul”. Não estamos dizendo que $S$ tem conhecimento por familiaridade, afinal, ele pode nunca ter ido ao Rio Grande do Sul e nem a Porto Alegre, nem que ele tem conhecimento por habilidade, mas que ele conhece o conteúdo desta afirmação.

Estes três tipos de conhecimento têm funções específicas dentro de um processo de ensino. O conhecimento por familiaridade é um tipo muito usado por professores que ensinam as crianças a reconhecerem coisas como a associação entre nomes de cores e as próprias cores representadas por tal nome, mesmo que elas ainda não saibam ler. Elas também são ensinadas a reconhecerem figuras de animais. Este é um tipo de conhecimento usado, por exemplo, em jogos de memória, onde devemos reconhecer duas figuras semelhantes e seus respectivos lugares para podermos virar as cartas certas. O jogo da 
memória é usado por muitos professores para desenvolver nas crianças o conhecimento por familiaridade (UCHÔA, 2012).

Quando o professor tem em mente que o conceito de conhecimento não é unívoco, mas que ao usarmos tal conceito podemos estar falando de três sentidos diferentes, sua aplicação aos alunos pode ser mais eficaz. Já vimos algumas aplicações dos conceitos de conhecimento por familiaridade e de conhecimento por habilidade (UCHÔA, 2012). É essencial, para nossa fundamentação de uma didática baseada em virtude, que não seja negligenciado tal distinção, pois quando dizemos que a principal função do professor é transmitir, na medida do possível, e mediar a relação entre o conhecimento científico e o aprendizado do estudante, devemos ter em mente qual tipo de conhecimento pode ser transmitido e como podemos fazer para que o aluno possa aprendê-lo.

Um dos conceitos centrais para modelo didático aqui apresentado é o de conhecimento por habilidade (knowhow). Em vista de tais propósitos, utilizo novamente algumas ideias presentes na filosofia de Ryle:

Existem certos paralelismos entre know-how e know-that. Falamos em aprender a tocar um instrumento e falamos de aprender que algo é o caso; de averiguar como se podam árvores e de averiguar se houve determinado acampamento romano em certo lugar. Podemos admirar como e podemos admirar que. Por outro lado, nunca dizemos que alguém crê, ou opina, como. Na medida em que é correto perguntar pelos fundamentos ou razões que 
ORIENTAÇ̃̃ES METODOLÓGICAS PARA UM ENSINO DE FILOSOFIA...

fazem alguém aceitar uma proposição, tal questão não pode acontecer no que diz respeito a sua habilidade de jogar cartas ou de investir dinheiro (RYLE, 1949, p. 28).

Seguindo tal raciocínio, o conhecimento por habilidade não é somente um objeto de estudo de disciplinas como artes e educação física, mas a habilidade é parte fundamental do aprendizado do aluno, sendo ele prático ou teórico. $\mathrm{O}$ que quero dizer pode ser resumido da seguinte forma: desenvolver uma virtude intelectual é, em partes, uma habilidade. Como veremos, uma das características centrais da noção de virtude é que ela é assimilada e aprendida por repetição, e não meramente por descrição. Assim, podemos eliminar completamente de uma prática virtuosa uma ideia que é compartilhada como um ditado popular que diz "faça o que eu digo, mas não faça o que eu faço".

Também podemos extrair da filosofia de Ryle, como já foi mencionado anteriormente, sua posição anti-intelectualista, que é uma característica típica da noção de virtude. O autor faz questão de deixar claro que a prática eficiente precede a teoria. Assim, a aplicação de métodos é produto de uma investigação crítica.

Foi sabido que Aristóteles (que foi o primeiro a formular as regras para o raciocinar correto) que ele e os demais raciocinavam às vezes inteligentemente e às vezes não. No que se segue, é possível realizar inteligentemente certas operações sem que seja possível ter em conta as proposições que determinam como executá-las. Algumas ações inteligentes não 
estão reguladas pelo conhecimento prévio dos princípios que as regem (Ryle, 1949, p.30).

Vimos que o conhecimento de conteúdo é apenas uma forma de conhecimento, mas é sobre esse que o professor deve, em grande parte, repousar seu ensino, pois o conhecimento proposicional é o único conhecimento capaz de ser transmitido de forma direta. Mas o papel do professor não pode ser reduzido à transmissão do que ele aprendeu de modo proposicional para o modo proposicional que o aluno aprende.

Como veremos, Zagzebski substitui a meta epistêmica tradicional, presente em Platão e Aristóteles, de que o objetivo do empreendimento filosófico como um todo é ter crença verdadeira, pelo conceito de compreensão. Isso implica em uma integração dos três tipos de conhecimento; e apesar do conhecimento proposicional ser o único capaz de ser integramente transmitido, é impossível que ocorra a compreensão sem haver conhecimento por habilidade e familiaridade. A autora busca justificar que compreensão surge da ideia grega de techne, ou seja, de atividades práticas que não são puramente cognitivas, envolvendo o entendimento do todo em suas partes interligadas, incluindo, portanto, a representação não proposicional do mundo. Compreensão, segundo ela, resultaria do exercício daquilo que Aristóteles define como phronesis (sabedoria prática): uma qualidade racional que leva à verdade no tocante às ações relacionadas com os bens humanos. Essa seria uma virtude intelectual que regula as demais virtudes promovendo o entendimento também das estruturas não proposicionais da realidade, algo essencialmente diferente do conhecimento vinculado a um objeto proposicional, como entende a análise tradicional. 
Em acordo com a noção de virtude presente em Zagzebski, veremos que o conhecimento é visto de um modo um tanto quanto divergente da tradição. Assim como o conhecimento não pode ser reduzido ao conhecimento proposicional, mas sim integrado com a "sabedoria", a relação entre epistemologia e ética é salientada e, segundo a autora, tais conceitos são inseparáveis.

\section{SOBRE CONHECER, APRENDER, ENSINAR E TER UM BOM CARÁTER INTELECTUAL}

Pretendo agora apresentar as posições gerais de Zagzebski sobre a noção de virtudes intelectuais, mostrando como podemos conectar algumas das considerações da autora sobre as virtudes com tudo o que foi dito até então, complementando, assim, nossa orientação metodológica para uma didática baseada em virtudes intelectuais. Primeiramente, é importante notar que "virtude" não é um conceito técnico, assim não é tão simples oferecer uma definição precisa de tal conceito. Para a autora, não ser definível é uma das virtudes do conceito de virtude.

Um dos propósitos de Zagzebski é lidar com virtudes morais e intelectuais sob uma única teoria e mostrar que essa teoria pode ser utilizada para a análise de alguns conceitos principais da epistemologia normativa, incluindo os conceitos de conhecimento e crença justificada (ZAGZEBSKI, 1996, p.14). A autora pretende desenvolver um modelo de epistemologia elaborado a partir do modelo da ética das virtudes aristotélica. Veremos, assim, que a avaliação 
epistemológica, antes de mais nada, é uma subárea da avaliação ética. Em vista de nossos propósitos, podemos dizer que a relação ensino-aprendizagem é também uma subárea de nossas práticas, não simplesmente um processo teórico de aquisição e transmissão de conhecimento.

É importante lembrar que, segundo Aristóteles, são dois os tipos de virtudes, as morais e as intelectuais ${ }^{4}$. A virtude intelectual é adquirida através do ensino, e assim, necessita de experiência e tempo. A virtude moral é adquirida, por sua vez, com resultado do hábito. Este se tornou o procedimento padrão pelo qual a filosofia conduziu grande parte de suas investigações: as virtudes se dividem em dois grupos, e é ao grupo das virtudes morais que se dedica o grosso das atenções. Todavia, Zagzebski irá optar por um caminho alternativo: as virtudes intelectuais não são um tipo distinto de virtude. Para a autora, as características que distinguem os dois tipos de virtudes não são capazes de sustentar tal divisão, e as virtudes intelectuais devem ser tratadas como um subconjunto das virtudes morais, no sentido aristotélico desta noção. Como ela afirma:

Eu argumentarei que uma virtude intelectual não difere de certas virtudes morais mais do que uma virtude moral difere de outra virtude moral, que os processos relacionados aos dois tipos de virtudes não funcionam independentemente, e que a tentativa de analisá-las em dois campos distintos da filosofia acaba por distorcer fortemente a natureza de ambas. Virtudes intelectuais são mais bem compreendidas como formas de virtudes morais. Zagzebski elabora 
ORIENTAÇ̃̃ES METODOLÓGICAS PARA UM ENSINO DE FILOSOFIA...

uma teoria baseada em virtude e baseada no ato, não um modelo consequencialista, como grande maioria dos modelos epistemológicos contemporâneos (ZAGZEBSKI, 1996, p.139).

Retomando novamente a filosofia de Aristóteles, podemos encontrar um argumento auxiliar para a sustentação da separação das virtudes em duas espécies sugerido na Ética à Nicômaco. Ele se baseia na ideia de que virtudes intelectuais são passíveis de ensino, enquanto as morais são hábitos adquiridos pelo exercício. Entretanto, Zagzebski imagina que "os estágios do aprendizado das virtudes intelectuais são exatamente paralelos aos estágios de aprendizagem das virtudes morais, como descritos por Aristóteles" (ZAGZEBSKI, 1996, p.150) - ou seja, as virtudes intelectuais também podem ser aprendidas por meio da imitação das pessoas virtuosas e da gradativa formação de hábitos em relação a certos sentimentos ou ações. Esse processo também inclui a imitação e a formação de hábitos (e o desenvolvimento de habilidades) relacionados a cada virtude particular. Retomando aqui o que foi dito anteriormente nas considerações iniciais, encontramos mais algumas razões para escolher a "nova roupagem" da concepção de virtude oferecida por Zagzebski ao invés da concepção clássica de Aristóteles.

Uma ideia central na proposta apresentada é alterar o modo como geralmente é conhecido o processo de ensino enquanto um processo meramente teórico, desvinculado das relações e avaliações éticas. A filosofia tradicionalmente tem considerado o ato como objeto de avaliação da ética, 
e a crença como o objeto da epistemologia. A proposta de Zagzebski é, segundo sua própria avaliação, original: em substituição a qualidade de crenças como primeiro objeto de avaliação, sua teoria das virtudes se ocupará primeiramente das características internas da pessoa:

A reação das pessoas comuns à impropriedade epistêmica não consiste apenas em dizer que a crença de uma pessoa é injustificada, mas em direcionar a avaliação para a pessoa mesma, denominando-a de [possuir uma] "mente estreita", "descuidado", "intelectualmente covarde", "rasteiro", "desatento", "preconceituoso", "rígido" ou "obtuso" (...). É claro que as crenças formadas como resultado destes defeitos são avaliadas negativamente, mas quaisquer termos para esta avaliação negativa, tais como "injustificado" ou "irracional", falham em informar qualquer outra coisa além da avaliação negativa isolada (ZAGZEBSKI, 1996, p 17).

Outra vantagem da teoria de Zagzebski é não tratar conceitos epistemológicos como impessoais. A autora sustenta que a epistemologia contemporânea é "impessoal", enquanto foca sobre valores epistêmicos que são impessoais: "o valor que consiste na posse da verdade e o valor da racionalidade e da crença justificada" (ZAGZEBSKI, 1996, p. 22.). Há, porém, outro valor epistêmico tão importante quanto estes, que é a sabedoria, e este valor não é impessoal, já que a sabedoria deve ser desenvolvida por cada indivíduo em particular. "A sabedoria, entendida como a posse harmônica das diversas virtudes, unifica as proposições 
conhecidas, unifica suas motivações e seus valores" (ZAGZEBSKI, 1996, p. 22). A sabedoria, neste sentido, não pode ser mal utilizada; o conhecimento, certamente, pode.

Mas como podemos compreender a noção de conhecimento a partir de concepções de virtude? Zagzebski dá a seguinte definição para o conceito de conhecimento: "conhecimento é o contato cognitivo com a realidade resultante de virtude intelectual" (ZAGZEBSKI, 1996, p. 271). Um ato de virtude é um ato em que existe uma imitação do comportamento das pessoas virtuosas e que consegue atingir seu objetivo por essa razão.

Desse modo, tanto as virtudes morais quanto as intelectuais deverão ser compreendidas e assimiladas de maneiras semelhantes. Como exemplo, temos as virtudes da compaixão, da confiança e da compreensão, que podem, em linhas gerais, ser definidas da seguinte maneira: a virtude da compaixão é uma característica que inclui a disposição emocional de aliviar o sofrimento dos outros, e o faz de maneira segura. A virtude da confiança é a característica de incluir a disposição emocional de confiar naqueles e apenas naqueles que sejam dignos de confiança, e o faz de maneira segura. A virtude da compreensão é a característica que inclui a disposição emocional de se estar aberto a visões dos outros, mesmo que elas entrem em conflito com as nossas, e o faz de maneira segura (ZAGZEBSKI, 2012).

Às vezes, um ato ou uma crença têm valor positivo simplesmente por ser o que uma pessoa virtuosa normalmente faria nas circunstâncias, sejam ou não virtuosamente motivados. Há um sentido de correto quando dizemos que a pessoa fez a coisa correta ao dar o 406 
troco certo para o comprador, mesmo que ela não tenha sido motivada por preocupações morais. Paralelamente, há um sentido de justificado quando dizemos que uma pessoa tem uma crença justificada ao acreditar que a Terra é redonda mesmo que ela não tenha construído razões para acreditar nisso por si só. Também avaliamos crenças e atos a partir da motivação do agente. Um ato ou crença que seja virtuosamente motivado merece crédito, embora quase sempre os qualifiquemos, mesmo que o ato não envolva o fazer a coisa certa e a crença não envolva o acreditar na coisa certa (ZAGZEBSKI, 2012).

É importante ressaltar que não é necessário que o agente possua determinada virtude para fazer um ato de virtude. Uma das condições de Aristóteles para a posse de virtude é que a característica deve estar profundamente arraigada. Como Zagzebski afirma:

Nesse caso, pessoas que estão aprendendo as virtudes não possuem uma dada virtude, contudo, não vejo razão para pensar que elas não possam realizar atos de virtude, ou seja, atos que sejam tão laudáveis quanto um ato pode ser em relação à virtude em questão (ZAGZEBSKI, 2012, p. 182).

Geralmente, em nossas práticas epistêmicas tanto de ensino como de aprendizagem, temos a tendência a pensar o conhecimento como uma realização própria, o que raramente acontece. $O$ fato de nosso conhecimento depender do conhecimento e da virtude intelectual de uma grande quantidade de pessoas em nossa comunidade 
intelectual, bem como de um universo cooperativo, possibilita que fique claro que não podemos isolar as condições para o conhecimento em um conjunto de propriedades independentes do conhecedor, muito menos em um conjunto de propriedades sobre as quais o conhecedor tenha controle (ZAGZEBSKI, 2012, p. 183).

\section{CONSIDERAÇÕES FINAIS}

Desse modo, podemos afirmar que conhecer é fruto da realização de um processo virtuoso no qual uma diversidade de fatores estão envolvidos no processo, tanto fatores externos, como o "universo cooperativo" envolvido em nossa comunidade intelectual, quanto processos internos, como a capacidade de produzir e compreender o conhecimento como resultado de uma habilidade cognitiva, uma virtude intelectual. Como vimos, o conhecimento agora é visto como o contato cognitivo com a realidade resultante de virtude intelectual.

Podemos dizer também que aprender éo resultado de uma mediação entre o mundo e nossa mente através de processos cognitivos virtuosos. É de fundamental importância notar aqui uma implicação desta tese. A informação apreendida pelo aluno, ou seja, o conteúdo proposicional assimilado, nunca é virtuoso ou não simplesmente em razão de seu conteúdo. É claro que é importante que a crença nesse conteúdo seja uma crença verdadeira, mas como vimos, a crença verdadeira, por si mesma, não contém mérito algum, a crença pode ser verdadeira até mesmo por um processo 
de sorte. Com a substituição da meta epistêmica da busca pela verdade, pela compreensão, vemos que o que é mais importante no aprendizado do aluno não é exatamente o conteúdo daquilo que é aprendido, mas o processo pelo o qual o aluno veio a acreditar naquela proposição. Por exemplo, acreditar em um conteúdo do tipo "a terra gira em torno do sol" ou "o assassinato é errado", não é louvável em si mesmo, pois tais conclusões podem ser fruto de um processo não virtuoso. Ou seja, o papel do professor deve ser estimular as atividades cognitivas de modo que desenvolva em seus alunos a capacidade de formar e justificar crenças verdadeiras por meio de um processo virtuoso.

Para concluir, a função última e essencial do que foi apresentado aqui é ser uma orientação para o ensinar. Essa é a função, por excelência, do professor. Não porque o aluno não possa ensinar algo, mas porque um modelo de toda forma de aprendizado se estrutura na figura do agente virtuoso, aquele que será o objeto de inspiração para o desenvolvimento e assimilação de novas virtudes. Isso não significa que o aluno não possua virtudes, mas que elas não devem estar tão arraigadas quanto no professor, que cumprirá a função de mestre. Como vimos no pensamento de Zagzebski, não quer dizer que aqueles que estão aprendendo as virtudes não possuam uma dada virtude. Um ato de virtude é um ato em que existe uma imitação do comportamento das pessoas virtuosas e que consegue atingir seu objetivo por essa razão. 
ORIENTAÇÕES METODOLÓGICAS PARA UM ENSINO DE FILOSOFIA...

\section{NOTAS}

${ }^{1}$ Mestrando em Filosofia pela Universidade Federal de Pelotas. E-mail: matheus.lrui@gmail.com

${ }^{2}$ Anti-intelectualismo é posição que acredita que nem todo conhecimento pode ser reduzido ao conhecimento descritivo, conhecimento de informações. Essa tese aparece na filosofia de Ryle, em que o autor busca delimitar sua posição contra uma posição tradicionalmente reconhecida na filosofia, do tipo dualista cartesiana, que o autor chama de 'intelectualistas'. ${ }^{3}$ É possível ter acesso à reflexão acerca do conceito em Os problemas da Filosofia (2005).

${ }^{4}$ Podemos conferir essa posição do autor no Livro I, II e VI da Ética a Nicômaco. 


\section{REFERÊNCIAS}

ARISTÓTElES. Ética à Nicômaco. Coleção os Pensadores. São Paulo: Nova Cultural, 1991.

GETTIER, E. Is true justified belief knowledge? In: Analysis, vol.23, nº, 1963, p.121- 123.

LUZ, A. M. Conhecimento e Justificação: Problemas de Epistemologia Contemporânea. Pelotas: NEPFil online, 2013.

RUSS, J. Os métodos em Filosofia. Petrópolis: Editora Vozes, 2010.

RUSSEL, B. Os problemas da Filosofia. Tradução Jamir Conte. Florianópolis: Edições 70, 2005.

RYLE, G. The Concept of Mind. London: Penguin Books, 1949.

UCHÔA, B. E. Epistemologia Analítica na educação. In: Filosofia e Educação, v. 04, no 01, 2012, p. 177 - 2012.

ZAGZEBSKI, L. Virtues of the Mind: A Inquiry into the Nature of Virtue and the Ethical Foundations of Knowledge. New York: Cambridge University Press, 1996.

ZAGZEBSKI, L. O que é o conhecimento? In: Compêndio de Epistemologia. Org. John Greco e Ernest Sosa. $2^{\circ}$ edição. São Paulo: Edições Loyola, 2012. 